\title{
KARAKTERISTIK ARUS LAUT DI PELABUHAN PANTOLOAN KOTA PALU SULAWESI TENGAH
}

\author{
Ayusari Wahyuni $^{1 *}$, Sri Ningsih ${ }^{2}$, Rahmaniah $^{1}$ \\ ${ }^{1}$ Jurusan Fisika \\ Fakultas Sains dan Teknologi UIN Alauddin Makassar \\ Jl. Sultan Alauddin No. 63, Kabupaten Gowa, Sulawesi Selatan. 92113 \\ ${ }^{2}$ Jurusan Teknik Sipil, Fakultas Teknik \\ Universitas Muhammmadiyah Luwuk \\ E-mail: ayusari_wahyuni@uin-alauddin.ac.id
}

\begin{abstract}
Port construction at Pantoloan has influenced the condition of port and its environment. The hidro-oceanography process has influenced the condition of water, especialy to the current. This research was aimed to know the characteristic of current at Pantoloan, Palu, Central Sulawesi. The method used in this research was the measurement of current using a Floater. Data analysis of the floater current and position or coordinates of the floater were recorded on GPS. The results showed that the average of current velocity at high tide at the study site was $0.176 \mathrm{~m} / \mathrm{s}$ with $221^{\circ}$ to the to the Southwest and the average of the current speed at low tide was 0.178 $\mathrm{m} / \mathrm{s}$ with $310^{\circ}$ from the north to the northwest. Current speed at low tide is relatively weak compared to current speed at high tide.
\end{abstract}

Keywords: current characteristic, current tidal, Pantoloan port, Palu

\section{PENDAHULUAN}

$\mathrm{P}$ elabuhan Pantoloan merupakan pelabuhan utama di Provinsi Sulawesi Tengah yang terbuka untuk pelayaran dalam dan luar negeri sekaligus merupakan pintu gerbang utama perekonomian Provinsi Sulawesi Tengah. Sebelum Pelabuhan Pantoloan dibangun, yang menjadi pelabuhan utama Provinsi Sulawesi Tengah adalah Pelabuhan Donggala sejak tahun 1964 (Nasril, 2019). Faktor-faktor hidro-oseaonografi seperti gelombang, arus laut dan pasang surut sangat berpengaruh terhadap kondisi di suatu perairan (Indrayanti et al., 2014). Penelitian mengenai gelombang air laut sangatlah beragam seperti yang telah dilakukan Duan et al. (2019), Tian et al. (2020) dan Wang et al. (2020). Arus laut (sea current) adalah perpindahan massa air dari satu tempat menuju tempat lain, yang disebabkan oleh berbagai faktor seperti gradien tekanan, hembusan angin, perbedaan densitas, atau pasang surut (Tanto et al., 2017) dan salah satu aspek oseanografi yang penting untuk mengetahui hidrodinamika dari suatu perairan adalah pola pergerakan arus. Selain faktor pergerakan arus laut, pasang surut juga mengambil peran penting dalam pengembangan pelabuhan. Pasang surut adalah fluktuasi muka air laut sebagai fungsi waktu karena adanya gaya tarik benda-benda di langit, terutama matahari dan bulan terhadap massa air laut di bumi. Meskipun massa di bulan jauh lebih dekat, maka pengaruh gaya tarik bulan terhadap bumi lebih besar dari pada pengaruh gaya tarik matahari (Korto et al., 2015). Informasi pasang surut sangat penting di dalam perencanaan pelabuhan dan perlindungan pada daerah pesisir salah satunya daerah pantai Pantoloan. 
Penelitian mengenai arus laut dilakukan untuk mengetahui pola pergerakan arus. Informasi tentang arus tersebut sangat berguna dalam berbagai kepentingan seperti, untuk bahan pertimbangan dalam pembangunan dermaga pelabuhan, bangunan lepas pantai maupun dekat pantai (drilling rig dan pipa-pipa yang akan dipasang di dasar laut), budidaya perairan dan pemilihan lokasi yang paling memungkinkan untuk pembangunan pembangkit tenaga listrik (Nugroho et al., 2007). Berdasarkan beberapa kajian di atas, penelitian ini dianggap perlu dalam mengetahui karakteristik arus di sekitar pelabuhan Pantoloan, Palu, Sulawesi Tengah.

\section{METODE PENELITIAN}

Alat yang digunakan untuk mengukur arus adalah Floater Current Meter (FCM) yang dihubungkan dengan GPS sebagai pencatat posisi floater (Sudarto et al., 2013). Data tersebut akan dilihat dan dicatat pada monitor GPS yang terpasang di perahu dengan kabel. Posisi awal dari alat floater ini dicatat kemudian dilepaskan ke laut dan dibiarkan terhanyut, setiap selang waktu tertentu posisi floater ini dicatat kembali. Pengamatan dilakukan pada tanggal 12-13 Agustus 2019 pada 14 titik lokasi pada saat laut pasang dan 9 lokasi titik sampling pada kondisi surut. Pengamatan dilakukan pada kedalaman perairan $8-50 \mathrm{~m}$. Data posisi geografis (koordinat) untuk setiap titik pengukuran dicatat selama 2 kali pengulangan. Dalam selang waktu yang ditentukan, perpindahan FCM yang terjadi merupakan jarak gerak arus, dengan asumsi bahwa untuk jarak pertama yaitu perpindahan dari koordinat pertama ke koordinat kedua, sedangkan jarak kedua adalah hasil dari perpindahan koordinat kedua ke koordinat ketiga. Lokasi dan proses pengukuran arus dapat dilihat pada Gambar 1a dan 1 b.
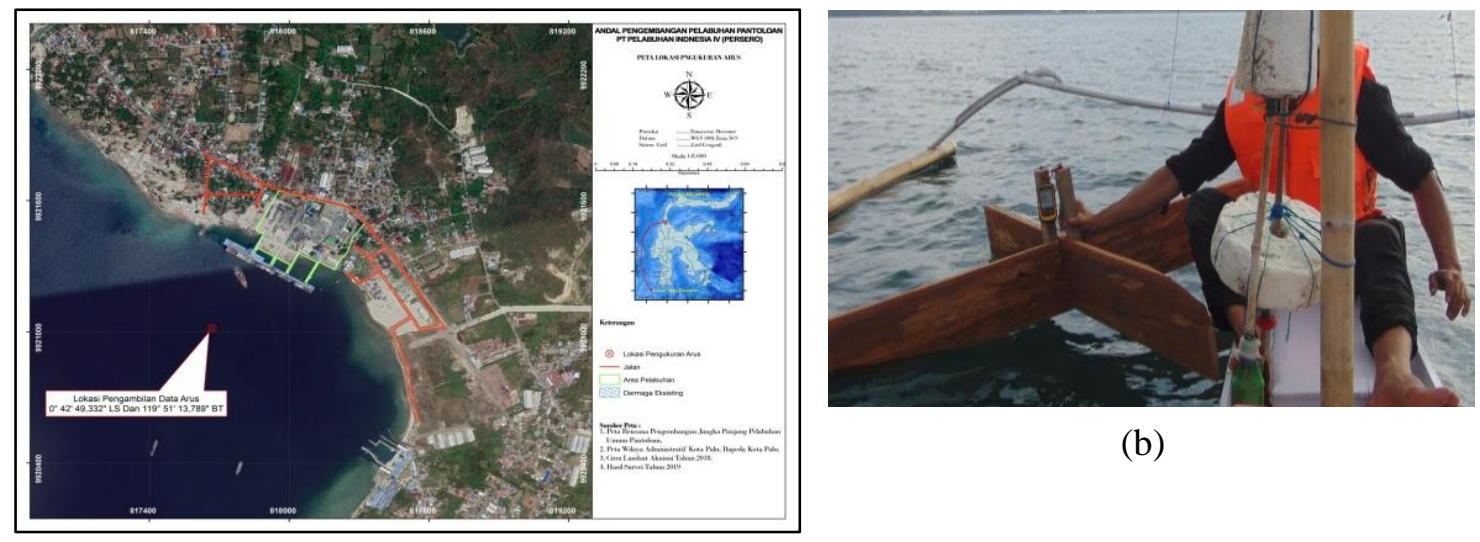

(b)

(a)

Gambar 1. (a) Peta lokasi pengukuran arus (b) proses pengambilan data

(Sumber: Hasil Pengukuran Lapangan, 2019)

Metode analisis data arus floater, posisi atau koordinat floater setiap saat terekam pada Global Positioning System (GPS). Dengan diketahuinya posisi floater yang terekam oleh GPS, maka kecepatan dan arah arus dapat diketahui. Kecepatan arus yang terukur adalah kecepatan rerata, yang merupakan kontribusi dari pasang surut dan gelombang. Jika diketahui posisi awal floater adalah X1, Y1, dan setelah selang waktu $\Delta \mathrm{t}$, posisi floater yang terekam pada GPS adalah X2, Y2, maka kecepatan arusnya (v) adalah: 


$$
V=\frac{\sqrt{\left(X_{2}-X_{1}\right)^{2}+\left(Y_{2}-Y_{1}\right)^{2}}}{\Delta t}
$$

Arah arus $(\alpha)$ setiap saat dapat dihitung dengan formula:

$$
\alpha=\operatorname{Arctan}\left[\frac{\left(Y_{2}-Y_{1}\right)}{\left(X_{2}-X_{1}\right)}\right]
$$

\section{HASIL DAN PEMBAHASAN}

Data hasil pengukuran arus pada saat pasang dan surut di lokasi studi dapat dilihat pada Tabel 1 dan Tabel 2.

Tabel 1. Raw Data Pengukuran Arus Pasang

\begin{tabular}{cccc}
\hline $\begin{array}{c}\text { Titik } \\
\text { Pengukuran }\end{array}$ & Koordinat & $\begin{array}{c}\text { Waktu } \\
\text { Tempuh }\end{array}$ & Arah \\
\hline 1 & 50 M 8179389913606 & $0: 07: 13$ & 224 \\
2 & 50 M 817922 9913590 & $0: 04: 20$ & 208 \\
3 & 50 M 817909 9913565 & $0: 04: 59$ & 246 \\
4 & 50 M 817886 9913555 & $0: 04: 16$ & 261 \\
5 & 50 M 8178539913550 & $0: 04: 47$ & 241 \\
6 & 50 M 817821 9913532 & $0: 03: 44$ & 220 \\
7 & 50 M 817796 9913503 & $0: 03: 14$ & 211 \\
8 & 50 M 817773 9913466 & $0: 02: 53$ & 220 \\
9 & 50 M 817745 9913432 & $0: 03: 10$ & 215 \\
10 & 50 M 817721 9913399 & $0: 03: 12$ & 209 \\
11 & 50 M 817698 9913361 & $0: 03: 13$ & 212 \\
12 & 50 M 817678 9913324 & $0: 03: 46$ & 215 \\
13 & 50 M 817657 9913290 & $0: 03: 23$ & 204 \\
14 & 50 M 817632 9913256 & $0: 01: 15$ & \\
\hline
\end{tabular}

Tabel 2. Raw Data Pengukuran Arus Surut

\begin{tabular}{cccc}
\hline $\begin{array}{c}\text { Titik } \\
\text { Pengukuran }\end{array}$ & Koordinat & $\begin{array}{c}\text { Waktu } \\
\text { Tempuh }\end{array}$ & Arah \\
\hline 1 & 50 M 818022 9913690 & $0: 05: 14$ & 344 \\
2 & 50 M 8180109913732 & $0: 04: 02$ & 341 \\
3 & 50 M 817996 9913770 & $0: 04: 09$ & 350 \\
4 & 50 M 817989 9913811 & $0: 03: 35$ & 357 \\
5 & 50 M 817987 9913857 & $0: 03: 32$ & 347 \\
6 & 50 M 817976 9913903 & $0: 03: 24$ & 0 \\
7 & 50 M 817976 9913951 & $0: 04: 28$ & 356 \\
8 & 50 M 817974 9913994 & $0: 04: 59$ & 341
\end{tabular}


Tabel 1 menunjukkan bahwa kegiatan pengukuran arus pada kondisi pasang dilakukan di 14 titik sampling. Waktu tempuh paling lama terjadi pada titik lokasi 1 dengan vektor arus dominan $246^{\circ}$. Lamanya durasi ini disebabkan relatif kecilnya kecepatan arus, yakni sebesar $0,053 \mathrm{~m} / \mathrm{s}$. Kecepatan arus yang relatif kecil terjadi pada kedalaman lebih dangkal, yakni sebesar 8-10 m. Sementara durasi paling rendah terjadi pada titik lokasi sampling 14 dengan waktu tempuh 01 '15'. Vektor arus bergerak ke arah $204^{\circ}$ dengan kecepatan arus sebesar 0,267 m/s dan kedalaman sebesar 35-40 m.

Pada Tabel 2 menunjukkan bahwa kegiatan pengukuran pada kondisi surut di lakukan di 9 titik sampling. Pada lokasi 1 merupakan lokasi dengan waktu tempuh paling lama, yakni 05'14', Kondisi dipengaruhi oleh kecepatan arus yang relatif sebesar $0,13 \mathrm{~m} / \mathrm{s}$. Sementara pada lokasi 9 kecepatan arus sebesar $0,23 \mathrm{~m} / \mathrm{s}$. Kedua kondisi ini menggambarkan bahwa semakin dalam kolom perairan, maka semakin besar magnitude kecepatannya. Menurut Tanto et al., (2017), nilai kecepatan arus dapat mencapai maksimum ketika muka air laut sesaat akan menuju nilai tertinggi dan juga sesaat menuju surut terendah.

Dengan menggunakan persamaan 1 dan persamaan 2, data posisi dan waktu yang terekam pada floater dapat digunakan untuk mengetahui nilai kecepatan arus pada saat pasang dan surut. Hasil perhitungannya dapat dilihat pada Tabel 3 dan Tabel 4.

Tabel 3. Hasil Analisa Kecepatan Arus Pasang

\begin{tabular}{cccc}
\hline \multicolumn{2}{c}{ Koordinat Pengukuran Arus } & & \\
(UTM) & Kecepatan $(\mathbf{m} / \mathbf{s})$ & Arah (Degrees) \\
\hline $\mathbf{X}$ & 9913606 & 0.0531 & 224 \\
817938 & 9913590 & 0.1077 & 208 \\
817922 & 9913565 & 0.0836 & 246 \\
817909 & 9913555 & 0.1289 & 261 \\
817886 & 9913550 & 0.1289 & 241 \\
817821 & 9913532 & 0.1696 & 220 \\
817796 & 9913503 & 0.2268 & 211 \\
817773 & 9913466 & 0.2543 & 220 \\
817745 & 9913432 & 0.2158 & 215 \\
817721 & 9913399 & 0.2344 & 209 \\
817698 & 9913361 & 0.2124 & 212 \\
817678 & 9913324 & 0.1814 & 204 \\
817657 & 9913290 & 0.2069 & 221 \\
817632 & 9913256 & 0.2667 & Relatif ke Arah Barat Daya \\
\hline \multicolumn{5}{c}{ Average } & $\mathbf{0 . 0 5 3}$ & (Menuju Teluk) \\
\hline
\end{tabular}


Tabel 4. Hasil Analisa Kecepatan Arus Surut

\begin{tabular}{cccc}
\hline \multicolumn{2}{c}{ Koordinat Pengukuran Arus (UTM) } & $\begin{array}{l}\text { Kecepatan } \\
(\mathbf{m} / \mathbf{s})\end{array}$ & Arah (Degrees) \\
$\mathbf{X}$ & $\mathbf{Y}$ & & \\
\hline 818022 & 9913690 & 0.1369 & 344 \\
818010 & 9913732 & 0.1694 & 341 \\
817996 & 9913770 & 0.1687 & 350 \\
817989 & 9913811 & 0.214 & 357 \\
817987 & 9913857 & 0.2264 & 347 \\
817976 & 9913903 & 0.2353 & 0 \\
817976 & 9913951 & 0.1604 & 356 \\
817974 & 9913994 & 0.1405 & 341 \\
817960 & 9914033 & 0.1462 & 353 \\
\hline \multicolumn{5}{c}{ Min } & $\mathbf{0 . 1 3 5}$ & $\mathbf{3 1 0}$ \\
\hline & Mverage & $\mathbf{0 . 1 7 7 5}$ & Relatif ke Arah Barat \\
\hline
\end{tabular}

Tabel 3 memperlihatkan bahwa kecepatan arus minimun, rerata, dan maksimum pada saat pasang di lokasi studi masing-masing adalah $0.053 \mathrm{~m} / \mathrm{s} ; 0.1765 \mathrm{~m} / \mathrm{s}$; dan $0.2667 \mathrm{~m} / \mathrm{s}$ dengan arah rerata adalah $221^{\circ}$ dari utara atau relatif ke arah barat daya. Adapun data hasil pengukuran ketika kondisi surut, kecepatan arus minimun, rerata, dan maksimum pada saat surut di lokasi studi masing-masing adalah $0.135 \mathrm{~m} / \mathrm{s} ; 0.1775 \mathrm{~m} / \mathrm{s}$; dan $0.2353 \mathrm{~m} / \mathrm{s}$ dengan arah rerata adalah 310 dari utara atau relatif ke arah barat laut. Kondisi ini dapat dilihat pada Tabel 4. Kecepatan arus saat surut yang terjadi pada daerah studi relatif lemah dibandingkan kecepatan arus pada saat pasang. Adapun adapun peta arah arus lokasi studi dapat dilihat pada Gambar 2.

Secara teori, kecepatan arus pasang lebih kecil dari pada kecepatan arus saat surut, akan tetapi pada kondisi ini berbeda dikarenakan lokasi pengambilan sampel memiliki titik yang berbeda ketika terjadi pasang. Lokasi pengambilan sampel pada saat surut berada pada perairan yang lebih dalam dengan menggunakan metode pengambilan sampling cenderung vertikal ke arah laut dalam. Semakin dalam perairan, magnitude kecepatan arus relatif semakin besar.

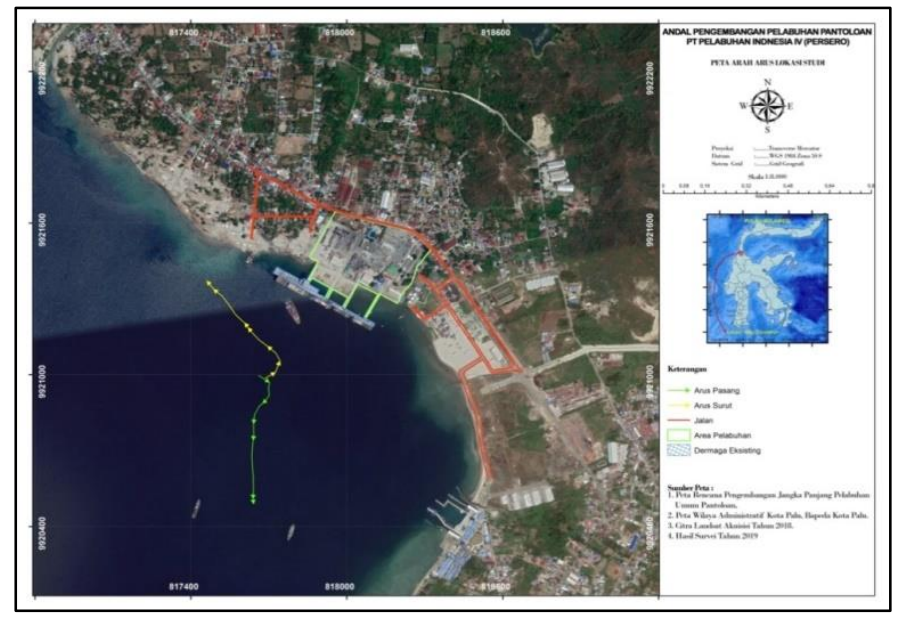

Gambar 2. Arah arus di lokasi penelitian 


\section{KESIMPULAN}

Berdasarkan hasil penelitian menunjukan bahwa distribusi pergerakan arus laut pada saat pasang ke arah barat daya (menuju teluk $221^{\circ}$ ) adalah $0.176 \mathrm{~m} / \mathrm{s}$ dengan dan hasil rata-rata kecepatan arus pada saat surut adalah $0.178 \mathrm{~m} / \mathrm{s}$ pada arah $310^{\circ} \mathrm{ke}$ arah barat laut. Kecepatan arus saat surut lemah dibandingkan kecepatan arus pada saat pasang.

\section{DAFTAR PUSTAKA}

Duan, C., Dong, S., \& Wang, Z. (2019). Wave climate analysis in the ice-free waters of Kara Sea. Regional Studies in Marine Science, 30, 100719. https://doi.org/10.1016/j.rsma.2019.100719.

Indrayanti, E., Kelautan, J. I., Diponegoro, U., Arus, K., Pasut, A., \& Kaliwungu, P. (2014). Online di : http://ejournal-sl.undip.ac.id/index.php/jose STUDI POLA DAN KARATERISTIK ARUS LAUT DI PERAIRAN, 3, 16-25.

Korto, J., Jasin, M. I., \& Mamoto, J. D. (2015). Analisis pasang surut di pantai nuangan (desa iyok) boltim dengan metode admiralty. Sipil Statistik, 3(6), 391-402.

Nasril, C. (2019). Kajian Upaya Peningkatan Produksi Bongkar Muat Di Pelabuhan Pantoloan Dalam Rangka Menekan Lama Kapal di Tambatan. Warta Penelitian Perhubungan. https://doi.org/10.25104/warlit.v25i5.735

Nugroho, D., Ads, A., Oseanografi, P. S., Ilmu, J., Fpik, K., \& Semarang, U. (2007). Studi Pola Sirkulasi Arus Laut di Perairan Pantai Provinsi Sumatera Barat, 12(2), 79-92.

Sudarto, S., Patty, W., \& Tarumingkeng, A. A. (2013). Kondisi arus permukaan di perairan pantai: pengamatan dengan metode Lagrangian. Jurnal Ilmu Dan Teknologi Perikanan Tangkap, 1(3), 98102. https://doi.org/10.35800/jitpt.1.3.2013.2539

Tanto, T. Al, Wisha, U. J., Kusumah, G., Pranowo, W. S., \& Husrin, S. (2017). Karakteristik Arus Laut Perairan Teluk Benoa-Bali KARAKTERISTIK ARUS LAUT PERAIRAN TELUK BENOA - BALI ( Characteristics of $S$ ea Current in Benoa Bay Waters - Bali ). July.

Tian, W., Ni, X., Mao, Z., \& Zhang, T. (2020). Influence of surface waves on the hydrodynamic performance of a horizontal axis ocean current turbine. Renewable Energy, 158, 37-48. https://doi.org/10.1016/j.renene.2020.04.127

Wang, J., Dong, C., \& Yu, K. (2020). The influences of the Kuroshio on wave characteristics and wave energy distribution in the East China Sea. Deep-Sea Research Part I: Oceanographic Research Papers, 158, 103228. https://doi.org/10.1016/j.dsr.2020.103228 